\title{
Overwintering ability of young-of-the-year bluefish Pomatomus saltatrix: effect of ration and cohort of origin on survival
}

\author{
Joshua J. Slater ${ }^{1}$, Thomas E. Lankford Jr. ${ }^{1, *}$, Jeffrey A. Buckel ${ }^{2}$ \\ ${ }^{1}$ Department of Biology \& Marine Biology and Center for Marine Science, University of North Carolina Wilmington, \\ 601 S. College Road, Wilmington, North Carolina 28403, USA \\ ${ }^{2}$ Department of Zoology, Center for Marine Sciences and Technology, North Carolina State University, 303 College Circle, \\ Morehead City, North Carolina 28557, USA
}

\begin{abstract}
Bluefish Pomatomus saltatrix have experienced declines in recruitment and adult abundance along the US East Coast since the mid-1980s. At the onset of winter, young-of-the-year (YOY) bluefish exhibit a multimodal size distribution including larger, spring-spawned fish (spring cohort) and smaller, summer-spawned fish (summer cohort). Declines in the adult stock appear to coincide with declines in recruitment success of the summer cohort. We investigated the hypothesis that poor recruitment success of the summer cohort results from size-selective winter mortality. Winter mesocosm experiments were conducted to examine the effects of cohort of origin (spring vs. summer) and food availability (fed vs. unfed) on winter survival of YOY bluefish. Spring fish entered winter with significantly greater lipid reserves than summer fish. When fed, both cohorts stored lipids during late fall, depleted lipid reserves during winter, and experienced high overwinter survival. When starved, both cohorts mobilized lipids from multiple depots (liver, viscera, white muscle, red muscle, skin) and summer fish experienced starvation mortality $\sim 6 \mathrm{wk}$ prior to spring fish. Although summer fish were more susceptible to winter starvation than spring fish, their starvation endurance ( $>90 \%$ survival probability after 120 d) appeared more than adequate to survive natural winter conditions. Interestingly, spring fish suffered a brief mortality event during January when water temperatures dropped briefly below $6^{\circ} \mathrm{C}$, suggesting that larger individuals are less tolerant of acute cold stress. The remarkable starvation endurance of summer-spawned bluefish, coupled with their capacity for rapid lipid storage during fall and reduced rates of lipid depletion at low temperatures, implies that members of this cohort are physiologically well-equipped to survive their first winter of life. Our findings are inconsistent with the hypothesis that winter starvation accounts for decreased recruitment of the summer cohort to the western Atlantic stock.
\end{abstract}

KEY WORDS: Winter mortality $\cdot$ Starvation endurance $\cdot$ Recruitment $\cdot$ Lipid dynamics $\cdot$ Cold tolerance Resale or republication not permitted without written consent of the publisher

\section{INTRODUCTION}

Bluefish Pomatomus saltatrix inhabit coastal and estuarine habitats along the East Coast of North America from Nova Scotia to the Florida Keys (Kendall \& Walford 1979). Spawning and recruitment patterns of bluefish over this range are complex (Kendall \& Walford 1979, McBride et al. 1993, Smith et al. 1994, Munch \& Conover 2000), resulting in the production of multiple cohorts of offspring within each year-class (Nyman \& Conover 1988, Conover et al. 2003). These cohorts are termed spring-spawned, summerspawned, and fall-spawned (McBride et al. 1993). The spring cohort is composed of bluefish spawned in continental shelf waters of the South Atlantic Bight (SAB) in March-May, whereas the summer cohort contains individuals spawned later (June to August) in the Middle Atlantic Bight (MAB). The fall cohort includes 
bluefish presumably spawned from September to January (McBride et al. 1993). Spring-spawned bluefish recruit to estuarine nurseries in both the SAB and MAB (Kendall \& Walford 1979, McBride \& Conover 1991, McBride et al. 1993, Hare \& Cowen 1996), whereas summer-spawned bluefish appear restricted to the MAB (Kendall \& Walford 1979, Nyman \& Conover 1988, McBride \& Conover 1991). The spawning locations, nursery habitats and recruitment success of fallspawned bluefish are less clear.

The different cohorts of young-of-the-year (YOY) bluefish display similar growth rates during summer and fall, resulting in a multimodal size distribution of individuals at the end of the first growing season (Nyman \& Conover 1988, McBride \& Conover 1991, McBride et al. 1993). In the MAB, spring-spawned bluefish are substantially larger than summerspawned bluefish prior to their fall migration (Chiarella \& Conover 1990, McBride \& Conover 1991). Differences in body size attained by spring- vs. summer-spawned bluefish at the onset of winter may have important implications for survival and recruitment potential (Sogard 1997).

The western Atlantic bluefish stock has experienced dramatic declines in recruitment and adult abundance since the mid 1980s (Munch \& Conover 2000, Conover et al. 2003). The mechanisms responsible for these declines are unclear. Several researchers have analyzed bluefish scale patterns to estimate the relative contribution of cohorts to adult recruitment (Lassiter 1962, Chiarella \& Conover 1990). Lassiter (1962) found that both cohorts were equally present in a sample of Age 1 individuals from North Carolina. Recent studies in the MAB, however, indicate that spring-spawned bluefish currently contribute disproportionately to the adult stock (Chiarella \& Conover 1990). Summerspawned bluefish are rare as adults, despite being abundant as YOY (Conover et al. 2003). Thus, cohorts produced during summer and fall appear to be lost from the population sometime after their fall migration and before reaching Age 1 (Conover et al. 2003).

Several possible explanations exist for the apparent recruitment failure of summer-spawned bluefish. First, methods used to back-calculate the cohort of origin of adult bluefish might be flawed. However, these methods were recently validated (Conover et al. 2003). Second, the summer cohort may exhibit compensatory growth during winter, reaching sizes comparable to the spring cohort by Age 1 (Sogard 1997). This phenomenon would give the impression of the summer cohort's disappearance despite their presence in the adult population. Laboratory and field observations of juvenile bluefish growth do not support this explanation (McBride et al. 1993, Buckel et al. 1998, Morley et al. 2007). Third, the summer cohort may recruit to localities outside the MAB, i.e. the SAB. Lastly, the summer cohort may fail to recruit due to negative sizeselective overwinter mortality.

Winter represents a potentially stressful period for young fishes (Johnson \& Evans 1990). Winter mortality can be an important factor regulating recruitment success in fish populations (Shuter et al. 1980, Post \& Evans 1989, Lankford \& Targett 2001). Low winter temperatures may cause acute or chronic cold stress which can compromise survival (Thompson et al. 1991, Johnson \& Evans 1996, Schultz \& Conover 1999, Lankford \& Targett 2001). Prey limitation, reduced feeding, decreased digestion rates and high activity costs (e.g. migration) during winter may lead to exhaustion of energy reserves and starvation (Oliver et al. 1979, Cunjak et al. 1987, Post \& Evans 1989, Thompson et al. 1991, Sogard 1997, Hurst \& Conover 1998, Schultz \& Conover 1999). Starvation may also weaken individuals, increasing their susceptibility to predation (Furuta 1998, Skajaa et al. 2003). Smaller conspecifics are generally considered more vulnerable to winter starvation because of their higher metabolic intensity and reduced capacity for energy storage (Oliver et al. 1979, Post \& Evans 1989).

Here we test the hypothesis that size-selective winter mortality contributes to recruitment failure of summer-spawned juvenile bluefish. Winter mesocosm experiments were conducted on spring- and summerspawned bluefish with the following objectives: (1) to examine the starvation endurance ability of individuals from spring vs. summer cohorts; (2) to investigate the importance of prey availability to overwinter survival; (3) to describe the energetic response of juvenile bluefish to starvation; and (4) to develop indices of nutritional condition to assess the status of wild juvenile bluefish during winter.

\section{MATERIALS AND METHODS}

Mesocosm experiment. Experimental subjects were collected by hook and line from the Atlantic Intracoastal Waterway (ICW) at the University of North Carolina at Wilmington (UNCW) Center for Marine Science (CMS) and from Beaufort Inlet, NC during October and November 2001. Subjects were held in 20001 circular fiberglass tanks at the UNCW CMS. Tanks were supplied continuously with ambient flow-through seawater $\left(201 \mathrm{~min}^{-1}\right)$ obtained from the ICW. During acclimation, bluefish were fed to satiation once daily on a natural diet of bay anchovies Anchoa mitchilli and Atlantic silversides Menidia menidia collected locally.

Experiments were conducted in an outdoor mesocosm system consisting of 12 flow-through tanks (2000 l, $1.8 \mathrm{~m}$ diameter). A fully-crossed $2 \times 2$ factorial 
design was used to test for effects of cohort (spring SP vs. summer SU) and feeding regime (fed vs. unfed) on the overwinter survival ability of bluefish. On 19 November 2001, tanks were stocked with 15 SP or SU bluefish ( $\mathrm{n}=3$ replicate tanks per treatment combination). Cohort assignment was based on bimodal length/frequency distributions of YOY bluefish collected in NC during fall 2001 (Morley et al. 2007). Mean $( \pm \mathrm{SD})$ initial fork lengths (FL) of SP and SU bluefish were $264 \pm 16.6 \mathrm{~mm}$ and $206 \pm 12.0 \mathrm{~mm}$, respectively (Student's $t$-test, $\mathrm{p}<0.01$ ). Although subjects were not aged, they were assumed to represent individuals with spring vs. summer birth dates based on differences in body size.

On 19 November, unfed treatments were deprived of food. Fed treatments were given unlimited daily rations of bay anchovies and Atlantic silversides. Tanks were checked for mortalities at least twice daily and moribund individuals were stored at $-20^{\circ} \mathrm{C}$ for subsequent analyses. Tank temperatures were recorded at $30 \mathrm{~min}$ intervals throughout the experiment using a miniature data logger (Onset Computer Corp.). Water temperatures ranged from $<6$ to $32^{\circ} \mathrm{C}$ (Fig. 1) and salinities ranged from 23 to $34 \%$.

Bluefish were subsampled on Days 0, 10, 30 and 90 to monitor nutritional condition. On these days 3 ind. were removed haphazardly from each replicate tank, killed with MS-222 and frozen at $-20^{\circ} \mathrm{C}$. On Day 192 (31 May 2002) all surviving bluefish were killed.

Lipid and ash determination. Total nonpolar lipids were extracted from bluefish tissues using the Soxhlet dry extraction protocol described in Schultz \& Conover (1997) and Slater (2004). Nonpolar lipids were monitored because this class includes the triacylglycerols, which constitute the principal storage lipids of fishes (Jobling 2001a). Entire livers and 0.5 to $2.0 \mathrm{~g}$ samples of epaxial white muscle (WM) were removed from individual bluefish for lipid quantification. Additional

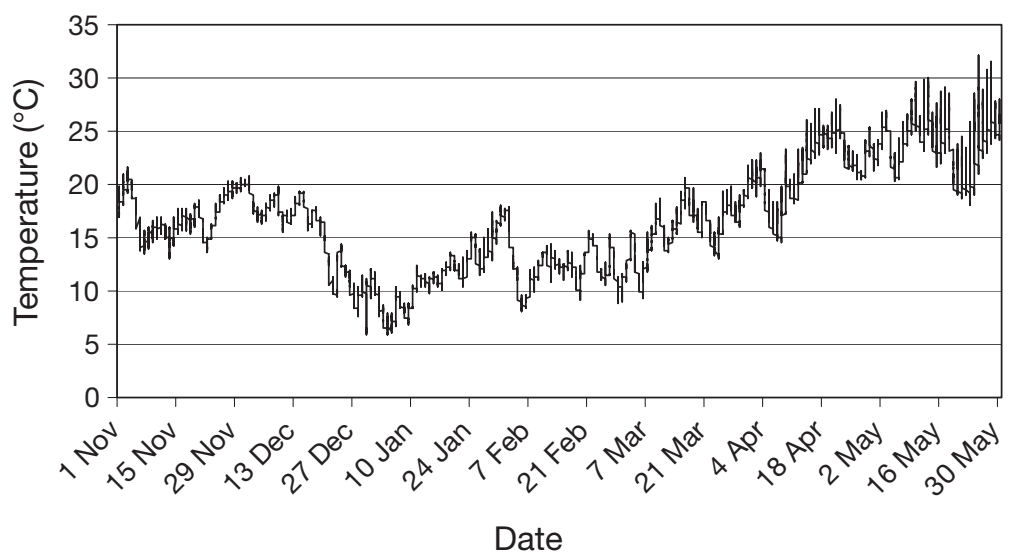

Fig. 1. Winter water temperatures experienced by bluefish in mesocosm tanks during overwinter experiments tissues - viscera, red muscle (RM), skin - and the remaining WM were dissected from subsamples of bluefish on each date to examine their role as depots for storage/mobilization of lipids. Tissue samples were dried at $60^{\circ} \mathrm{C}$, weighed, placed into cellulose thimbles and extracted in petroleum ether for $4 \mathrm{~h}$. Extracted tissues were re-dried and weighed, and total nonpolar lipid content was determined by mass difference (Slater 2004).

Fishes may utilize non-lipid energy stores (e.g. protein and glycogen) when starved (Jobling 2001b), in which case the inorganic (ash) fraction of their tissues would increase (Jobling 2001b, Slater 2004). We therefore measured the ash content of bluefish tissues as an additional indicator of nutritional condition. Lean (extracted) tissues were dried at $60^{\circ} \mathrm{C}$ for at least $48 \mathrm{~h}$, weighed, placed into pre-ashed quartz crucibles $(20 \mathrm{ml})$ and combusted at $450^{\circ} \mathrm{C}$ for $24 \mathrm{~h}$. Crucibles were then placed in a drying oven, cooled to $60^{\circ} \mathrm{C}$ and re-weighed. Ash content was expressed as a percentage of lean tissue dry mass.

Statistical analyses. Pre-winter lipid reservesspring vs. summer cohort: Initial lipid and ash data were analyzed using 2-way ANOVA to test for differences between cohorts and among body depots (liver, viscera, WM, RM, skin) prior to winter. Fed and unfed bluefish were combined within each cohort since Day 0 subsamples were taken prior to ration manipulation. Lipid content (g), lipid density (\%) and ash content were tested using separate ANOVAs. Correlation analyses (Pearson product-limit method, Bonferroniadjusted $\alpha=0.005$ ) were used to examine whether lipid content, lipid density and ash content were correlated among bluefish body depots.

Ration effects on condition of body depots: Day 0 , 10, 30 and 90 (SU cohort only) lipid and ash data were analyzed across all body depots using separate 1-way repeated-measures ANOVA within each treatmentspring fed (SP_F), summer fed (SU_F), spring unfed (SP_U) and summer unfed (SU_U) - to assess the role of different body depots in the storage/mobilization of lipids. Lipid content, lipid density and ash content were tested individually for each treatment. Due to insufficient sample sizes, final (Day 192) data were excluded from analyses.

Response of cohorts to winter starvation: Data from Days 0, 10, 30 and 90 were analyzed using repeated-measures ANOVA to test for effects of cohort, feeding treatment and time on liver condition ( $g$ dry mass per mm FL), liver lipid content $(\mathrm{g})$, liver lipid density (g lipid per g dry mass), liver ash con- 
tent, body condition (total wet mass/FL), WM lipid density (g lipid/g dry mass), WM ash content, and mean body length. The condition of SP_F and SU_F bluefish surviving on Day 192 was compared using student's $t$-tests. Numbers of survivors from unfed treatments were insufficient for statistical analysis.

Initial (Day 0) and final (Day 192) condition data for the SP_F, SP_U and SU_F treatments were compared using Student's $t$-tests to test for significant changes in condition over winter. The SU_U treatment was excluded from this analysis since no individuals survived to Day 192. Condition indices analyzed were as stated above.

Overwinter survival: Survival curves were calculated for each treatment combination using the Kaplan-Meier product-limit estimate method and compared statistically using the non-parametric MantelHaenzel log-rank test for censored data (Marubini \& Valsecchi 1995). After testing for tank effects within each treatment, data were pooled across replicate tanks and analyzed for treatment effects. Pair-wise comparisons were performed using Gehan's Wilcoxon test to isolate cohort and ration effects.

Starvation assessment of wild bluefish: Condition indices of starved mesocosm bluefish were compared to those of wild-caught bluefish using 1-way repeatedmeasures ANCOVA (covariate $=$ FL) to assess whether wild bluefish exhibited low condition levels indicative of starvation. Wild bluefish for this analysis were trawled from continental shelf (5 to $20 \mathrm{~m}$ depth) habitats in Onslow Bay, North Carolina, during February and May 2002 (Morley et al. 2007). Condition indices included liver dry mass, liver lipid and ash content, WM lipid density, WM ash content and total wet body mass.

All statistical analyses were performed in Statistica version 6.0 (StatSoft 2001) using a significance value of $\alpha=0.05$ unless otherwise stated. When appropriate, significant main effects were analyzed a posteriori with Tukey multiple comparison tests. Prior to analyses, data were tested for normality using Kolmogorov-Smirnov tests and for homogeneity of variances using Levene's tests. In cases where transformation did not correct normality violations or variance heterogeneity, untransformed data were reanalyzed nonparametrically (Mann-Whitney $U$-test or Kruskal-Wallis ANOVA).

\section{RESULTS}

\section{Pre-winter lipid reserves: spring vs. summer cohort}

Lipid content and density of YOY bluefish varied significantly ( $p<0.01$ ) among cohorts and body depots prior to winter (Fig. 2A,B). For SP fish, lipid content was highest in WM, followed by skin, RM, viscera and liver (Fig. 2A). SU fish displayed a similar pattern of lipid dis-

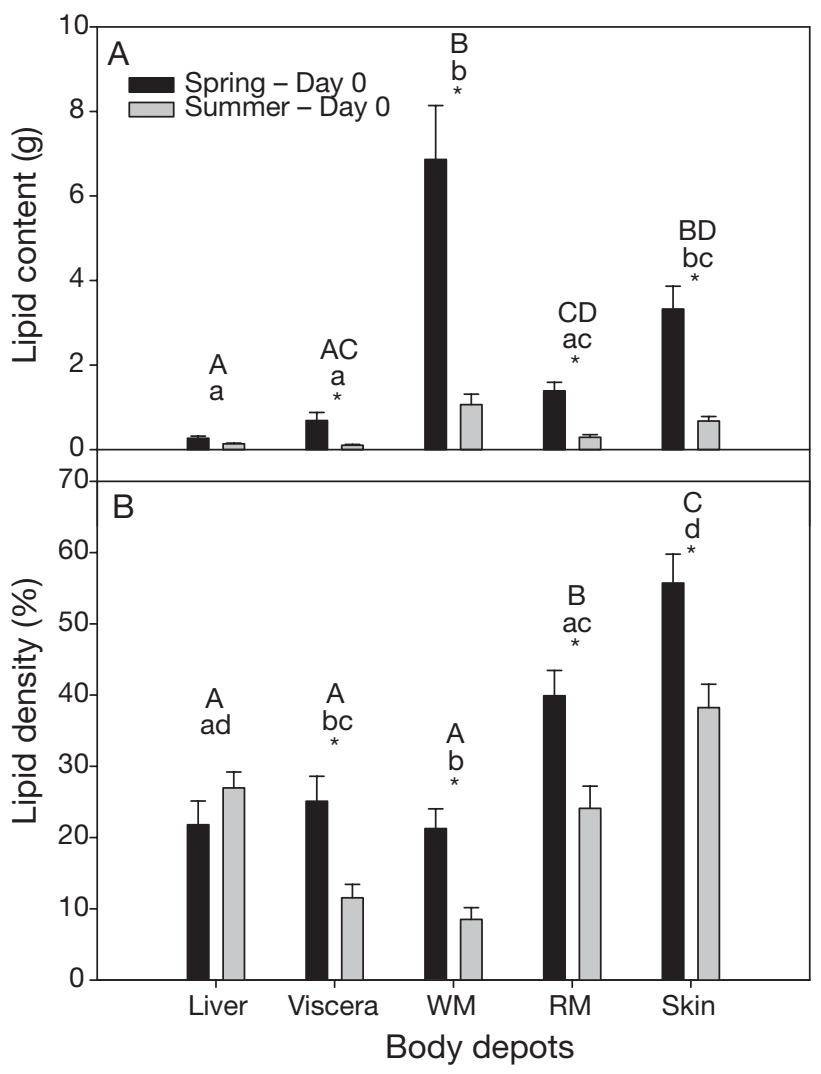

Fig. 2. Pomatomus saltatrix. Mean $( \pm \mathrm{SE})(\mathrm{A})$ lipid content and (B) lipid density of different body depots (WM and RM: white and red muscle, respectively) for spring vs. summer cohorts of young-of-the-year bluefish subsampled on Day 0 (19 Nov 2001). Mean values sharing same upper-case letter (spring bluefish only) or lower-case letter (summer bluefish only) are not significantly different. *Significant difference between cohorts within a given body depot (Tukey multiple comparisons tests, $\alpha=0.05$ )

tribution except that liver values were higher than viscera values (Fig. 2A). SP fish entered winter with significantly higher lipid contents than SU fish in all body depots except liver (cohort $\times$ depot interaction: $p=0.02$ ) (Fig. 2A). Initial lipid content was positively correlated across body depots for both SP and SU fish, correlation coefficients ranging from $r=0.59$ to 0.93 and $r=0.19$ to 0.94, respectively (Slater 2004). Mean initial ash content varied significantly among body depots $(p<0.01)$, but not between cohorts $(\mathrm{p}=0.33)$. For SP fish, mean ash content was lowest in liver, followed by skin, viscera, RM and WM. For SU fish, mean ash content was lowest in RM, followed by liver, WM, viscera and skin.

\section{Ration effects on condition of body depots}

When fed, SP fish increased their overall lipid content $(p=0.04)$ and density $(p=0.12)$ after $30 \mathrm{~d}$ (Fig. 3A-E). Lipid content increased in each body 


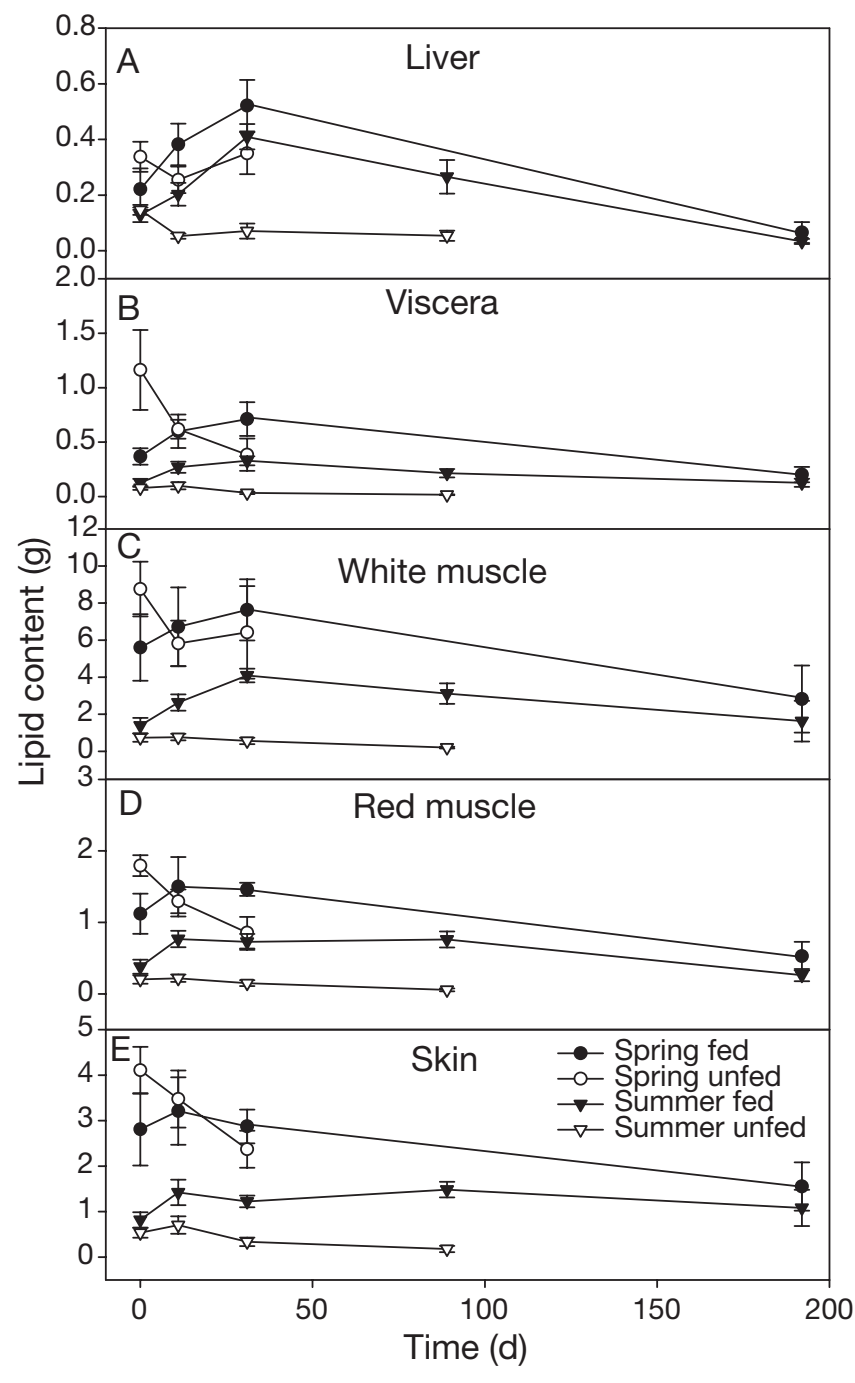

Fig. 3. Pomatomus saltatrix. Effects of cohort of origin (springvs. summer-spawned) and feeding status (fed vs. unfed) on mean $( \pm \mathrm{SE})$ lipid content of different body depots (A-E) of juvenile bluefish overwintering in mesocosm tanks

depot (except skin) at comparable rates (depot $\times$ time interactions: content, $p=0.97$; density, $p=0.99$; Fig. 3A-E). Mean ash content decreased significantly in all depots except viscera.

When fed, SU fish increased their overall lipid content $(p<0.01)$ and density $(p<0.01)$ after $90 \mathrm{~d}$ (Fig. 3A-E). Lipid content and density increased across body depots at similar rates (depot $\times$ time: content, $\mathrm{p}=$ 0.59; density, $\mathrm{p}=0.52$; Fig. 3A-E). Ash content decreased $(p<0.01)$ over time in viscera and RM, while increasing in liver, WM and skin.

When starved, SP fish exhibited declines in overall lipid content $(p<0.01)$ and density $(p<0.01)$ after $30 d$ (Figs. 3A-E). Ash content did not change significantly $(\mathrm{p}=0.90)$. Starved SP fish mobilized lipid from all depots at similar rates (depot $\times$ time: content, $\mathrm{p}=0.24$;
Fig. 3A-E). Lipid density (depot $\times$ time: $p<0.01$ ) decreased in all depots over time, except liver, while ash content $(p=0.03)$ increased over time in liver, viscera and RM but decreased in WM and skin.

When starved, SU fish decreased their overall lipid content $(\mathrm{p}<0.01)$ and density $(\mathrm{p}<0.01)$ after $90 \mathrm{~d}$ (Fig. 3A-E). While both lipid content and density decreased in each body depot, individual decreases were not significant (Fig. 3A-E). Ash content did not change significantly $(p=0.19)$. Starved SU fish mobilized lipid from all depots at similar rates (depot $\times$ time: content, $p=0.42$; density, $p=0.34$; Fig. 3A-E); however, their ash content $(\mathrm{p}<0.01)$ increased in liver, viscera, WM and RM, but decreased significantly in skin. Based on positive correlations between the condition of WM and all other depots with the exception of liver, further analyses focused on WM and liver depots.

\section{Response of cohorts to winter starvation}

Significant $(p<0.01)$ effects of feeding and cohort were noted for bluefish liver condition after $30 \mathrm{~d}$. When fed, both cohorts displayed a $100 \%$ increase in liver dry mass after $30 \mathrm{~d}$ and SP fish maintained a significantly higher value than SU fish (Fig. 4A). When starved, liver mass declined rapidly in both cohorts after $10 \mathrm{~d}$ and slowly thereafter (Fig. 4A). Mean liver mass decreased significantly in fed SU fish from Day 30 to Day 90 $(p<0.05)$ while values for unfed SU fish did not change (Fig. 4A). Fed SU fish displayed higher liver mass than unfed counterparts on Days 90 \& 192 (Fig. 4A). On Day 192 , livers of fed SP fish remained significantly heavier than those of fed SU fish ( $\mathrm{p}<0.05)$ (Fig. 4A).

There were significant effects of feeding $(p<0.01)$ and cohort $(\mathrm{p}<0.01)$ on liver lipid content (Fig. 4B). When fed, both cohorts displayed a $>133 \%$ increase in liver lipid content after $30 \mathrm{~d}$. When starved, liver lipid content decreased in both cohorts after $10 \mathrm{~d}$; however, neither change was significant. SP fish exhibited significantly higher liver lipid content than SU fish after $30 \mathrm{~d}$ of starvation. Neither fed nor unfed SU fish displayed changes in liver lipid content from Day 30 to Day 90 ( $p>0.75$; Fig. 4B). Fed SU fish had significantly higher liver lipid content than unfed SU fish after $90 \mathrm{~d}$ ( $p<0.05$ ). On Day 192, fed SP and SU fish displayed similar liver lipid content ( $\mathrm{p}=0.65$; Fig. 4B).

There were significant effects of feeding $(p<0.01)$ and near significant effects of cohort $(p=0.07)$ on liver lipid density. When fed, both cohorts displayed a 5\% increase in liver lipid density after $30 \mathrm{~d}$ (Fig. 4C). When starved, both cohorts displayed $>7 \%$ increase in liver lipid density after $30 \mathrm{~d}$. Overall, the livers of starved fish had higher lipid densities than those of fed fish, and this difference was most apparent for SP fish 


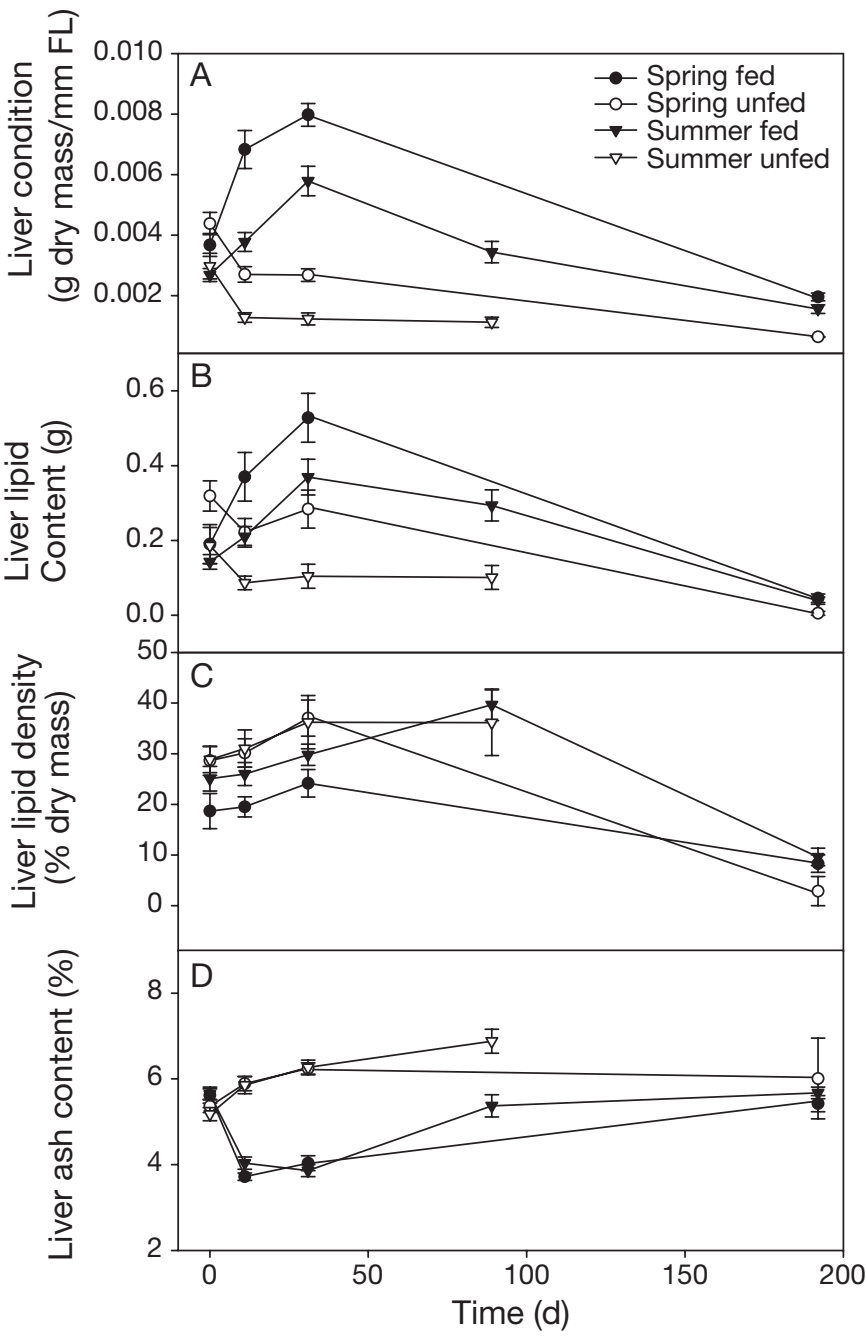

Fig. 4. Pomatomus saltatrix. Effects of cohort of origin (springvs. summer-spawned) and feeding status (fed vs. unfed) on mean $( \pm \mathrm{SD})(\mathrm{A})$ liver condition, (B) liver lipid content, $(\mathrm{C})$ liver lipid density, and (D) liver ash content of bluefish overwintering in mesocosm tanks

(Fig. 4C). For fed SU fish, liver lipid density increased $\sim 10 \%$ from Day 30 to Day 90, but this was not significant $(p=0.76)$. For unfed SU fish, liver lipid density did not change significantly from Day 30 to Day 90. On Day 192, fed SP and SU fish displayed similar liver lipid densities ( $p=0.60$; Fig. 4C).

There were significant effects of feeding $(p<0.01)$, but not cohort $(\mathrm{p}=0.95)$, on liver ash content. When fed, liver ash content declined markedly (>15\%) in both cohorts after $10 \mathrm{~d}$ (Fig. 4D). Liver ash content did not change significantly between Day 10 and Day 30 in fed fish from either cohort. When starved, both cohorts displayed a significant increase $(>10 \%)$ in liver ash content (Fig. 4D). For SU fish, liver ash content increased significantly from Day 30 to Day $90(p<0.01)$ when fed, but not significantly when starved $(p=0.34)$. After 90 d, fed SU fish had significantly lower ash con- tent than unfed SU fish. After $192 \mathrm{~d}$, fed SP and SU fish had similar liver ash contents $(p=0.28)$ (Fig. 4D).

There were significant effects of feeding $(p<0.01)$ and cohort $(p<0.01)$ on the body condition of bluefish after $30 \mathrm{~d}$ (Fig. 5A). Body condition of fed fish did not change significantly for either cohort after $30 \mathrm{~d}$, and SP fish exhibited significantly higher condition than SU fish (Fig. 5A). When starved, body condition did not change significantly in either cohort after $10 \mathrm{~d}$ but decreased significantly thereafter in SU fish $(p=0.02$; Fig. 5A). Starved SP fish maintained significantly higher body condition than starved SU fish after $30 \mathrm{~d}$ (Fig. 5A). For SU fish, body condition did not change significantly from Day 30 to Day 90 in either fed or unfed fish (Fig. 5A). Fed SU fish had significantly higher body condition than unfed SU fish after $90 \mathrm{~d}$ ( $p<0.01$ ) (Fig. 5A). After $192 \mathrm{~d}$, fed SP fish had significantly higher body condition than fed SU fish (Fig. 5A).

There were near significant effects of feeding ( $p=$ $0.05)$ and significant effects of cohort $(p<0.01)$ on the

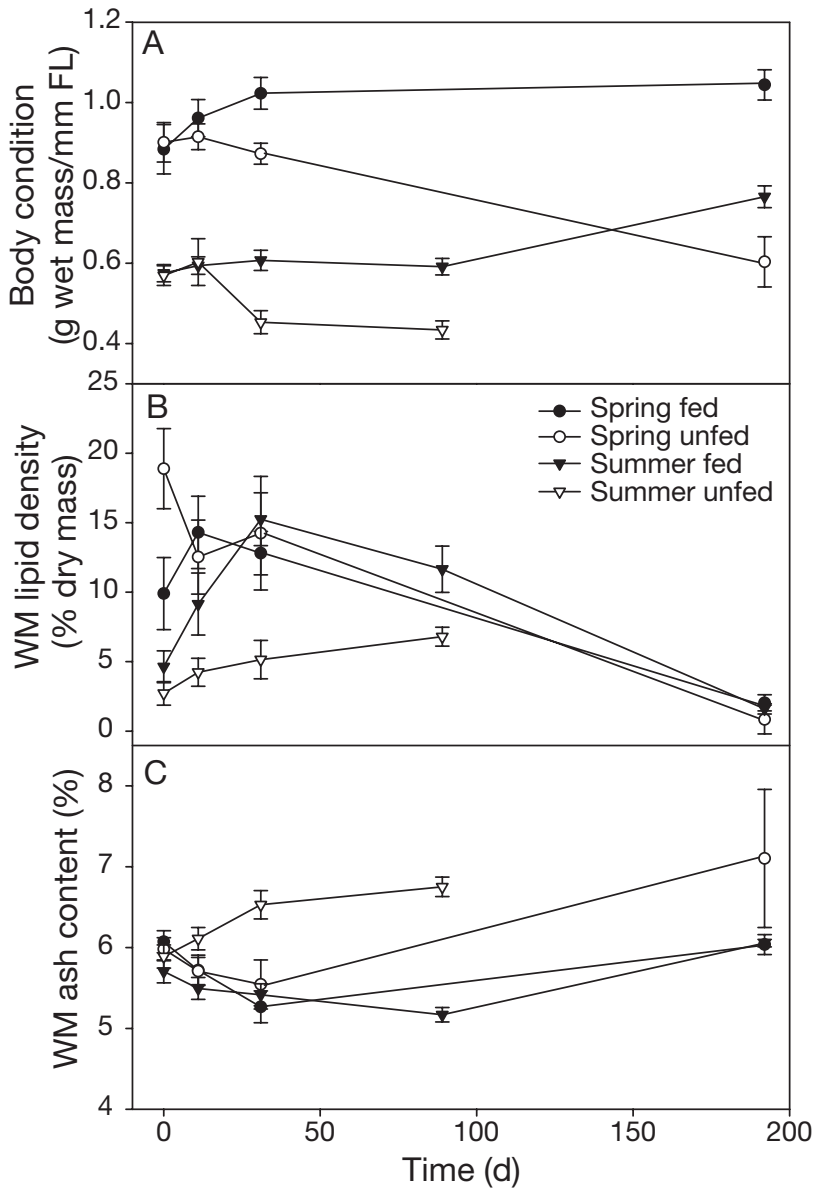

Fig. 5. Pomatomus saltatrix. Effects of cohort of origin (springvs. summer-spawned) and feeding status (fed vs. unfed) on mean $( \pm \mathrm{SD})(\mathrm{A})$ body condition, (B) white muscle (WM) lipid density, and (C) WM ash content of bluefish overwintering in mesocosm tanks 
WM lipid density of YOY bluefish (Fig. 5B). When fed, both cohorts increased WM lipid density after $30 \mathrm{~d}$; however, the increase was only significant for SU fish ( $p=0.03$ ). When starved, WM lipid density did not change significantly in either cohort after $30 \mathrm{~d}$. Overall, fed fish maintained higher lipid densities than starved fish and this difference was most apparent for the SU cohort. Also, SP fish had higher densities than SU fish, with this difference being most apparent when unfed (Fig. 5B). For fed SU bluefish, WM lipid density decreased from Day 30 to Day $90(p=0.90)$. For unfed SU fish, WM lipid density increased during this same period ( $p=0.06$ ) (Fig. 5B). Fed SU fish had significantly higher densities than unfed SU fish after $90 \mathrm{~d}$ ( $\mathrm{p}<$ 0.01). After $192 \mathrm{~d}$ there was no difference in WM lipid density between fed SP and SU fish ( $p=0.53$; Figs. 5B).

There were significant effects of feeding $(p<0.01)$, but not cohort $(p=0.20)$, on the WM ash content of YOY bluefish within $30 \mathrm{~d}$ (Fig. 5C). When fed, both cohorts had decreased WM ash content after $30 \mathrm{~d}$; the decrease in SP fish was near significant $(p=0.05)$ and the decrease in SU fish was not significant ( $p=0.99$; Fig. $5 C$ ). When starved, WM ash content decreased in SP fish and increased in SU fish after $30 \mathrm{~d}_{i}$ however, neither change was significant. Unfed SU fish exhibited significantly higher WM ash content than unfed SP fish after $30 \mathrm{~d}$ (Fig. 5C). WM ash content in both fed and unfed SU fish did not change significantly from Day 30 to Day 90. Fed SU fish had significantly lower WM ash content than unfed SU fish after $90 \mathrm{~d}(\mathrm{p}<0.01)$. After $192 \mathrm{~d}$, fed SP fish did not have significantly higher WM ash content than fed SU fish ( $p=0.89$; Fig. $5 \mathrm{C}$ ).

There were significant effects of cohort $(p<0.01)$, but not feeding $(p=0.47)$, on the mean FL of YOY bluefish within $30 \mathrm{~d}$. When fed, mean FL increased in SP fish after $30 d(p=0.46)$ but not in SU fish $(p=1.00)$. When starved, mean FL increased in SP fish after $30 \mathrm{~d}$ $(p=0.04)$ but not in SU fish ( $p=1.00)$. SP fish exhibited significantly higher mean FL than SU fish after $30 \mathrm{~d}$, regardless of feeding treatment. Mean FL in both fed and unfed SU fish did not change significantly between Days 30 and 90. Mean FL did not differ significantly between fed and unfed SU fish after $90 \mathrm{~d}$ ( $\mathrm{p}=$ 0.97). After $192 \mathrm{~d}$, fed SP fish remained significantly larger than fed SU fish $(p<0.01)$.

When fed, both cohorts lost condition over the course of the experiment. Liver condition, liver lipid content, liver lipid density and WM lipid density declined significantly in fed SP fish $(\mathrm{p}<0.01, \mathrm{p}<0.01, \mathrm{p}=0.01$, and $p=0.02$, respectively), while liver and WM ash content did not $(p=0.47$ and $p=0.85$, respectively; Figs. 4A-D, $5 \mathrm{~A}-\mathrm{B})$. Similar results were seen in fed SU fish, with the exception that WM ash content increased in this treatment $(p=0.04)$. Mean FL $( \pm$ SD) of fed SP fish increased significantly $(p=0.01)$ from Day $0(252 \pm$
$21.0 \mathrm{~mm})$ to Day $192(275 \pm 13.6 \mathrm{~mm})$. Mean FL $( \pm \mathrm{SD})$ of fed SU fish increased significantly $(p<0.01)$ from Day $0(206 \pm 13.2 \mathrm{~mm})$ to Day $192(238 \pm 9.6 \mathrm{~mm})$.

When starved, SP fish lost condition over the course of the experiment while SU fish did not survive. Liver condition, liver lipid content, liver lipid density and WM lipid density declined significantly in starved SP fish ( $p=0.03$ for all), while liver and WM ash content did not $(p=0.52$ and $p=0.13$, respectively; Figs. 4A-D, $5 \mathrm{~A}, \mathrm{~B})$. Mean FL $( \pm \mathrm{SD})$ of starved SP fish on Day $0(247$ $\pm 18.5 \mathrm{~mm})$ and Day $192(256 \pm 17.7 \mathrm{~mm})$ were not significantly different $(p=0.52)$.

\section{Overwinter survival}

Replicate survival curves for a given treatment combination did not differ significantly among tanks. Thus, replicate tanks were pooled to test for treatment effects on winter survival. Survival duration of bluefish differed significantly across treatments $(p=0.02$; Fig. 6$)$. Within each cohort, fed fish survived significantly longer than unfed fish (log-rank: $\mathrm{p}<0.01$ for SP, $\mathrm{p}<$ 0.01 for SU; Fig. 6). When starved, SP fish had a significantly higher probability of surviving until May than SU fish (Gehan's Wilcoxon: $p<0.01$; Fig. 6). Under starvation conditions, $50 \%$ of SU fish survived $>150 \mathrm{~d}$ (Fig. 6). When food was provided, survival probabilities did not differ significantly between cohorts (logrank: $\mathrm{p}=0.55$; Fig. 6 ).

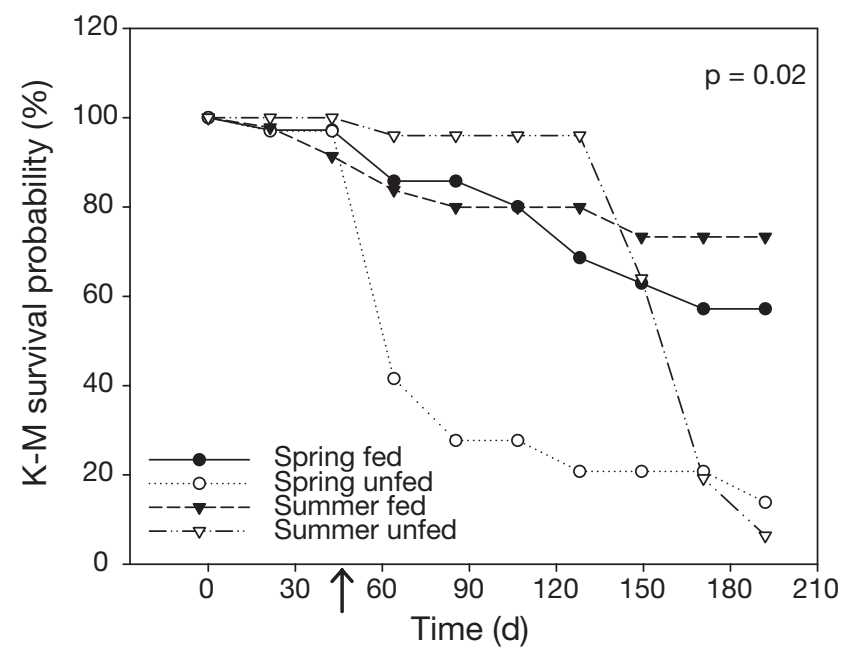

Fig. 6. Pomatomus saltatrix. Effects of cohort (spring- vs. summer-spawned) and ration (fed vs. unfed) on winter survival duration of young-of-the-year bluefish. Survival curves shown for each treatment combination are based on Kaplan-Meier (K-M) product-limit estimates averaged across replicates $(\mathrm{n}=$ 3 replicate tanks per treatment combination). $p$-value indicates results of Mantel log-rank tests comparing survival curves across treatments $(\alpha=0.05)$. Arrow indicates day when tank water temperatures dropped briefly below $6^{\circ} \mathrm{C}$ 


\section{Starvation assessment of wild bluefish}

Size-adjusted dry mass of liver for critically starved laboratory bluefish was significantly lower than values observed in wild bluefish during both February and May ( $\mathrm{p}<0.01$; Fig. 7A). Critically-starved laboratory bluefish also had significantly higher liver ash content than wild bluefish from February and May ( $p<0.01$ ) (Fig. 7B). Comparisons involving liver lipid content, WM lipid density, WM ash content and total mass failed Levene's test; however, graphical inspection of these data suggested that values for wild bluefish did not approach those of critically starved laboratory bluefish (Figs. 7C,D).

\section{DISCUSSION}

\section{Pre-winter lipid reserves: spring vs. summer cohort}

An important prediction of the overwinter starvation hypothesis for summer-spawned bluefish is that smaller fish would enter winter with lower lipid re-
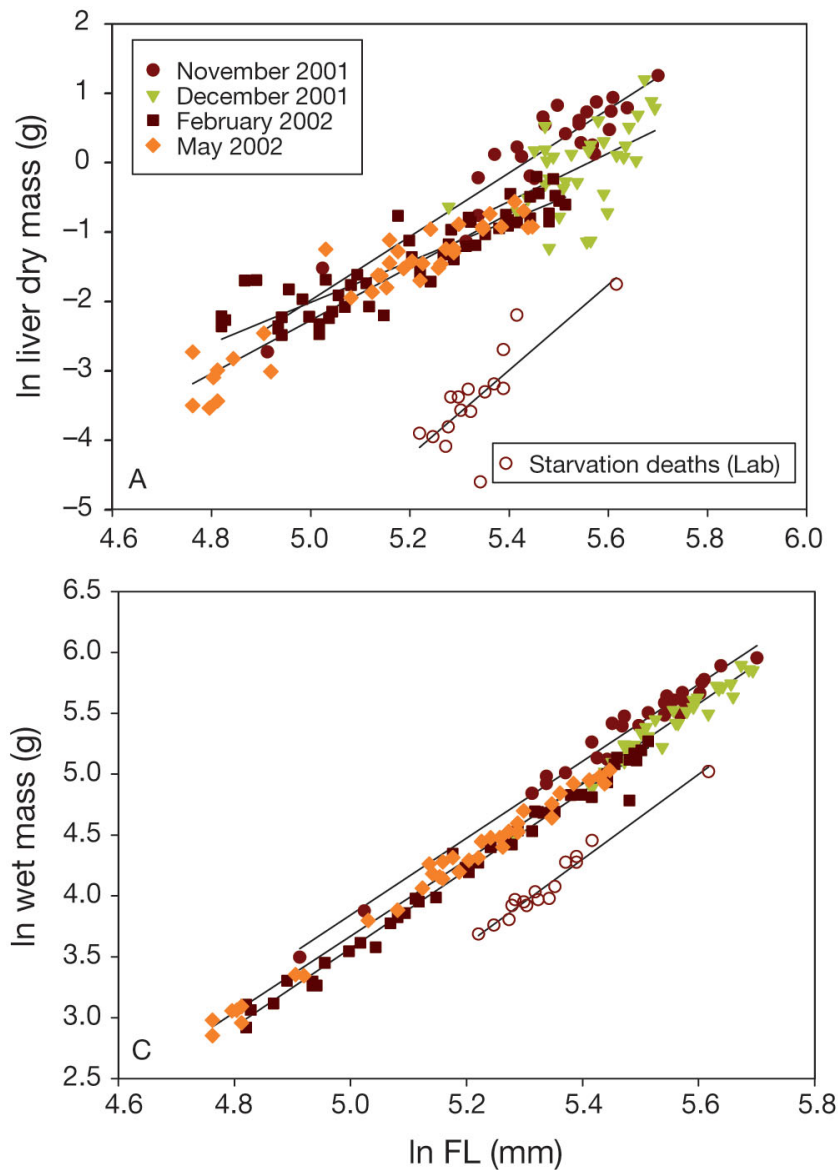

serves than larger, spring-spawned conspecifics. Previous researchers have documented this pattern for a variety of YOY fishes (Thompson et al. 1991, Miranda \& Hubbard 1994, Schultz \& Conover 1997, McCollum et al. 2003). Our findings for bluefish generally support this pattern as the SP cohort entered winter with significantly higher lipid content $(>4.75 \times)$ and lipid density $(>13 \%)$ than the SU cohort in 4 out of 5 body depots examined (viscera, WM, RM and skin). Interestingly, the livers of SP and SU spawned fish did not differ significantly in lipid content or lipid density, although SP liver lipid content was, on average, $1.5 \times$ greater than that of the SU cohort.

Fishes are known to store and metabolize lipids from multiple body depots. The relative importance of each depot may vary depending on species (Love 1980, Sheridan 1988). When analyzing lipid content of fishes, previous studies have typically focused on whole organisms or a subset of potential depots (Sheridan 1988). By monitoring the lipid content of various depots, we revealed that juvenile bluefish rely on multiple depots (liver, viscera, WM, RM, skin) for both storage and mobilization of lipid. Furthermore, we suggest
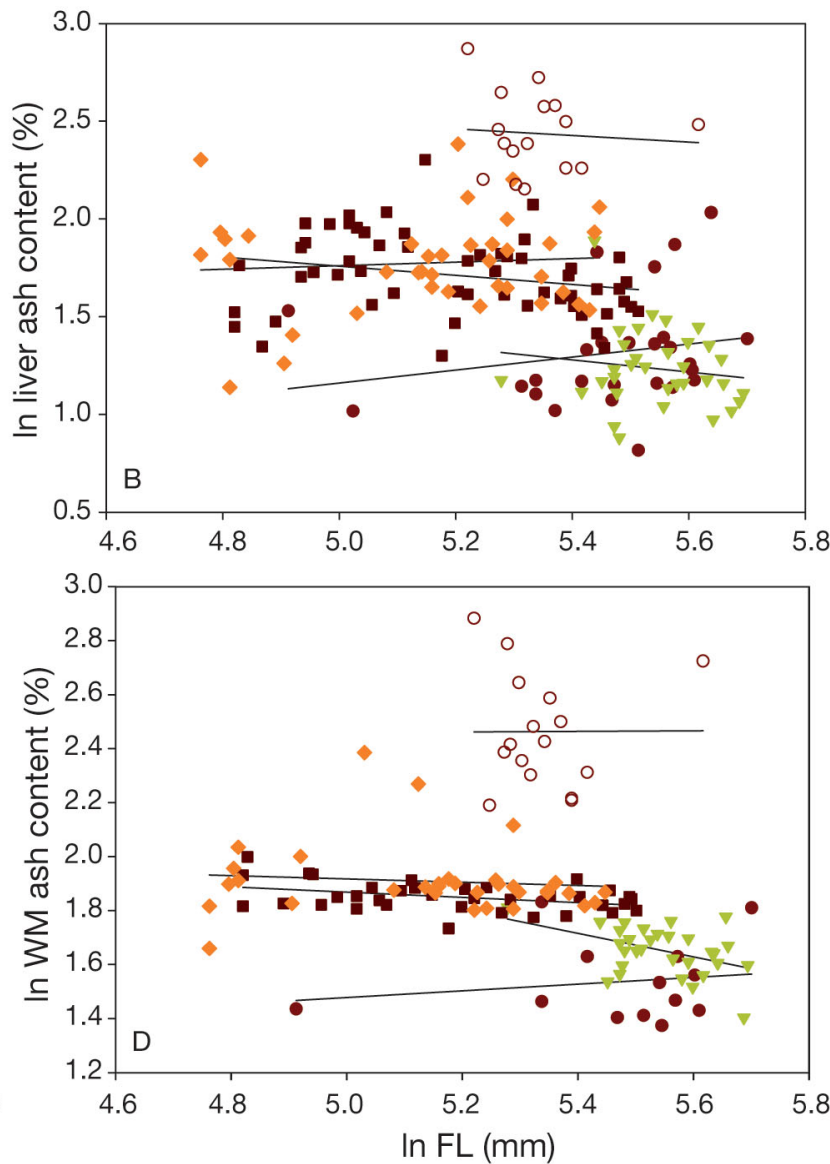

Fig. 7. Pomatomus saltatrix. Overwinter changes in energetic condition of wild bluefish (filled symbols) vs. starved mesocosm subjects (open circles). (A) Liver dry mass, (B) liver ash content, (C) total wet mass, (D) white muscle ash content 
that monitoring of WM and liver lipids provides a strong index of overall body lipids.

\section{Lipid depletion patterns: spring vs. summer cohort}

A second important prediction of the starvation hypothesis was that smaller, SU bluefish would deplete lipid reserves at faster rates than larger, SP bluefish (Post \& Evans 1989, Miranda \& Hubbard 1994, Schultz \& Conover 1999). Our results for bluefish do not support this prediction. When starved, SP and SU fish depleted lipid reserves at similar rates over the first $30 \mathrm{~d}$ of the experiment. Thereafter, SP fish depleted lipid more rapidly than SU fish. Interestingly, ash content of WM increased at faster rates in SU fish than SP fish, suggesting that SU fish may have depleted nonlipid reserves (e.g. protein or glycogen) in WM at a faster rate than SP fish. Although SP and SU fish depleted lipid reserves at similar rates, SU fish would still be expected to have lower starvation endurance because they enter winter with lower lipid reserves than SP fish (Thompson et al. 1991).

\section{Lipid storage patterns: spring vs. summer cohort}

Summer-spawned bluefish could conceivably compensate for lower lipid reserves at the onset of winter if they could store lipids more rapidly or efficiently than SP fish during winter. We found that when food was present both cohorts stored lipid at similar rates during late fall. There were no significant differences in rates of decrease for ash content in liver or WM over this time period, suggesting that both cohorts increased the organic content of their tissues at similar rates. These findings suggest that SU fish do not store lipids at faster rates than SP fish prior to winter.

Interestingly, fed bluefish had considerably lower lipid reserves in May than November and December, despite having access to unlimited prey throughout the winter. This seasonal depletion pattern has been reported for other fishes (Reimers 1963, Hunt 1969, Post \& Evans 1989, Thompson et al. 1991) and demonstrates the importance of lipid reserves for fueling routine metabolism during winter. In the presence of food, both cohorts appeared to selectively deplete lipid reserves rather than to maintain or synthesize new lipids. Cunjak et al. (1987) showed that cold temperatures reduce digestion and assimilation efficiency causing individuals to mobilize stored energy reserves to meet metabolic demands. While cold $\left(<15^{\circ} \mathrm{C}\right)$ temperatures occurred for bluefish subjects during January and February, it is surprising that lipid reserves remained virtually depleted in late May. Water tem- peratures in the mesocosm tanks during April and May $\left(>15^{\circ} \mathrm{C}\right)$ were within preferred ranges of bluefish and presumably suitable for feeding and energy storage (Lund \& Maltezos 1970, Morley et al. 2007). It is noteworthy that similar temperatures experienced by bluefish subjects during the previous fall were associated with rapid lipid storage by both cohorts.

Depletion of lipid reserves by bluefish during the spring may represent an intrinsic, seasonal strategy of energy allocation involving trade-offs between the competing processes of growth and storage (Schultz \& Conover 1997, Post \& Parkinson 2001). Once the threat of winter starvation ceases and food is no longer limiting, remaining energy reserves may be allocated to growth, reproduction and/or migration (Flath \& Diana 1985, Schultz \& Conover 1997, Jobling 2001b). Analyses of wild bluefish are consistent with our laboratory observations. For example, Morley et al. (2007) report that wild bluefish also depleted lipid reserves during April and May coincident with increases in body weight and gut fullness.

Depletion of lipid reserves in fed SP and SU fish also supports the 'defended energy level' hypothesis (Mrosovsky \& Sherry 1980, Metcalfe \& Thorpe 1992) in which individuals feed strategically to prevent their energy reserves from declining below a threshold level critical for survival. As energy reserves approach critical levels, individuals are predicted to increase consumption to defend their energy reserves (Metcalfe \& Thorpe 1992). Our results for bluefish are consistent with this hypothesis. Given that both cohorts depleted lipid reserves at similar rates when unfed, and SP fish entered winter with significantly greater reserves, SP fish should have displayed greater lipid reserves than SU fish following winter. In fact, lipid reserves of fed SP and SU fish were similar following winter. These findings are consistent with the 'defended energy level' hypothesis in that if SU fish fed selectively throughout winter when their lipid reserves approached a critical level, and SP fish, with their greater lipid reserves, chose not to feed, then the lipid reserves of SU fish would be comparable to those of SP fish by the end of the experiment. Seasonal patterns of energy depletion observed in wild bluefish also support this argument (Morley et al. 2007).

\section{Overwinter survival: spring vs. summer cohort}

Two other important predictions of the starvation hypothesis were that: (1) SU bluefish would survive winter better if food was present; and (2) SU bluefish would starve more rapidly than SP bluefish if food was limited (Post \& Evans 1989, Johnson \& Evans 1990, Thompson et al. 1991). Our data generally supported 
these predictions. Both SP and SU cohorts survived significantly longer when fed. When food was withheld, SU fish began to display starvation mortality approximately 6 wk earlier than SP fish. However, starvation mortality in SU fish was not observed until after 31 March (Day 127), well after winter had ended and feeding conditions in the wild would have likely improved. Furthermore, unfed SU fish had a $>60 \%$ survival probability by Day 150, after ca. 5 mo without food. Bluefish are not unique among fishes in their ability to endure long periods without food (Love 1980, Post \& Evans 1989, Johnson \& Evans 1990, Johnson \& Evans 1991, Thompson et al. 1991, Sogard \& Olla 2000). Although SU fish were more susceptible to winter starvation mortality than SP fish, their remarkable ability to endure starvation appears more than sufficient to enable overwintering in coastal waters of the South Atlantic Bight.

\section{Cohort responses to starvation vs. acute cold stress}

Spring-spawned bluefish suffered an acute mortality event during January 2002 when the passage of a cold front lowered water temperatures to $6^{\circ} \mathrm{C}$. Smaller, summer-spawned bluefish were not affected by this event. This observation suggests that smaller, latespawned SU bluefish may possess greater cold tolerance than larger SP fish. Similar findings have been reported for YOY Atlantic croaker (Lankford \& Targett 2001). Such differences in cold tolerance may have important implications for the winter habitat requirements and migratory patterns of SP versus SU bluefish. Greater cold tolerance may permit smaller SU fish to overwinter at higher latitudes and cooler temperatures where reduced metabolic expenditure could compensate for their lower energy reserves. Johnson \& Evans (1996) discussed such a trade-off between the risks of acute thermal stress at colder temperatures versus increased starvation risk at milder temperatures. Reduced migration distances and utilization of cooler water by SU bluefish during winter may effectively conserve energy reserves and increase the likelihood of winter survival (Hurst \& Conover 2001). Additional studies of the thermal physiology, temperature preferenda and winter distribution of young bluefish are required to further evaluate this hypothesis.

\section{Starvation assessment of wild bluefish}

Condition analyses of wild bluefish sampled during winter/spring 2002 revealed that they depleted lipid during the winter period but did not approach critical starvation levels exhibited by starved, mesocosm sub- jects. Condition indices of wild fish were significantly higher than those of critically starved mesocosm fish. In May, critically starved mesocosm fish had liver masses and total wet masses that were $\sim 50 \%$ of similar-sized wild fish. The ash content of liver and muscle tissues were also significantly higher in starved, mesocosm fish.

In summary, we explored the apparent recruitment failure of summer-spawned bluefish and whether this cohort is likely to experience size-selective winter mortality due to starvation. Given our observations that the SU cohort can store lipid rapidly during fall, deplete lipid slowly during winter, access multiple body depots for lipid storage and mobilization, and endure remarkable (>150 d) periods of winter starvation, we conclude that winter starvation is not a likely explanation for their failure to recruit. It is important to note that our experiments addressed the physiological capacity of bluefish to endure starvation and did not evaluate possible indirect effects of sublethal starvation on recruitment potential. However, we note that Morley et al. (2007) recently reported successful overwintering by both summer- and fall-spawned bluefish based on their presence in spring trawl surveys off North Carolina following both mild and severe winters. Additional studies of the winter ecology of juvenile bluefish, including the effects of activity level (i.e. migration costs), winter severity and pre-winter energy storage on winter survival, are needed to further evaluate the fate of summer- and fall-spawned bluefish.

Acknowledgements. We thank E. Schultz and S. Kinsey for advice regarding lipid quantification; J. Arnott, W. Collier and P. Ruderhausen for assistance with specimen collection; J. Morley for providing energetics data for wild bluefish; R. Moore and R. Deanes for maintenance of UNCW seawater facilities; and S. Wells for laboratory assistance. This research was supported by Award \# NA17FE2747 to J.A.B. and T.E.L. from the NOAA/NMFS/CMER Bluefish Research Program.

\section{LITERATURE CITED}

Buckel JA, Letcher BH, Conover DO (1998) Effects of a delayed onset of piscivory on the size of age-0 bluefish. Trans Am Fish Soc 127:576-587

Chiarella LA, Conover DO (1990) Spawning season and firstyear growth of adult bluefish from the New York Bight. Trans Am Fish Soc 119:455-462

Conover DO, Gilmore T, Munch SB (2003) Estimating the relative contribution of spring- and summer-spawned cohorts to the Atlantic coast bluefish stock. Trans Am Fish Soc 132:1117-1134

Cunjak RA, Curry RA, Power G (1987) Seasonal energy budget of brook trout in streams: implications of a possible deficit in early winter. Trans Am Fish Soc 116:817-828

Flath LE, Diana JS (1985) Seasonal energy dynamics of the alewife in southeastern Lake Michigan. Trans Am Fish Soc 114:328-337 
Furuta S (1998) Effects of starvation on feeding behavior and predation vulnerability of wild Japanese flounder juveniles. Bull Jap Soc Sci Fish 64:658-664

Hare JA, Cowen RK (1996) Transport mechanisms of larval and pelagic juvenile bluefish (Pomatomus saltatrix) from South Atlantic Bight spawning grounds to Middle Atlantic Bight nursery habitats. Limnol Oceanogr 41:1264-1280

Hunt R (1969) Overwinter survival of wild fingerling brook trout in Lawrence Creek, Wisconsin. J Fish Res Board Can 26:1473-1483

Hurst TP, Conover DO (1998) Winter mortality of young-ofthe-year Hudson River striped bass (Morone saxatilis): size-dependent patterns and effects on recruitment. Can J Fish Aquat Sci 55:1122-1130

Hurst TP, Conover DO (2001) Activity-related constraints on overwintering young-of-the-year striped bass (Morone saxatilis). Can J Zool 79:129-136

Jobling M (2001a) Feed composition and analysis. In: Houlihan D, Boujard T, Jobling $M$ (eds) Food intake in fish. Blackwell Science, Malden, MA, p 1-24

Jobling M (2001b) Nutrient partitioning and the influence of feed composition on body composition. In: Houlihan D, Boujard T, Jobling M (eds) Food intake in fish. Blackwell Science, Malden, MA, p 354-375

Johnson TB, Evans DO (1990) Size-dependent winter mortality of young-of-the-year white perch: climate warming and invasion of the Laurentian Great Lakes. Trans Am Fish Soc 119:301-313

Johnson TB, Evans DO (1991) Behavior, energetics, and associated mortality of young-of-the-year white perch Morone americana and yellow perch Perca flavescens under simulated winter conditions. Can J Fish Aquat Sci 48:672-680

Johnson TB, Evans DO (1996) Temperature constraints on overwinter survival of age-0 white perch. Trans Am Fish Soc 125:466-471

Kendall AW Jr, Walford LA (1979) Sources and distribution of bluefish, Pomatomus saltatrix, larvae and juveniles off the East Coast of the United States. Fish Bull 77:213-227

Lankford TE, Targett TE (2001) Low temperature tolerance of age 0 Atlantic croaker: recruitment implications for US Mid-Atlantic estuaries. Trans Am Fish Soc 130:236-249

Lassiter RR (1962) Life history aspects of the bluefish, Pomatomus saltatrix (Linnaeus), from the coast of North Carolina. MS thesis, North Carolina State University, Raleigh

Love RM (1980) The chemical biology of fishes, Vol. 2. Academic Press, New York

Lund WA Jr, Maltezos GC (1970) Movements and migration of the bluefish, Pomatomus saltatrix, tagged in waters of New York and southern New England. Trans Am Fish Soc 99:719-725

Marubini E, Valsecchi MG (1995) Analyzing survival data from clinical trails and observational studies. John Wiley \& Sons, New York

McBride RS, Conover DO (1991) Recruitment of young-ofthe-year bluefish Pomatomus saltatrix to the New York Bight: variation in abundance and growth of spring- and summer-spawned cohorts. Mar Ecol Prog Ser 78:205-216

McBride RS, Ross JL, Conover DO (1993) Recruitment of bluefish Pomatomus saltatrix to estuaries of the U.S. South Atlantic Bight. Fish Bull 91:389-395

McCollum AB, Bunnell DB, Stein RA (2003) Cold, northern winters: the importance of temperature to overwinter mortality of age-0 white crappies. Trans Am Fish Soc 132: 977-987

Metcalfe NB, Thorpe JE (1992) Anorexia and defended energy levels in over-wintering juvenile salmon. J Anim Ecol 61:175-181
Miranda LE, Hubbard WD (1994) Length-dependent winter survival and lipid composition of age-0 largemouth bass in Bay Springs Reservoir, Mississippi. Trans Am Fish Soc 123:80-87

Morley JW, Buckel JA, Lankford TE Jr (2007) Winter energy storage dynamics and cohort structure of young-of-theyear bluefish Pomatomus saltatrix off North Carolina. Mar Ecol Prog Ser 334:273-286

Mrosovsky N, Sherry DF (1980) Animal anorexias. Science 207:837-842

Munch SB, Conover DO (2000) Recruitment dynamics of bluefish (Pomatomus saltatrix) from Cape Hatteras to Cape Cod, 1973-1995. ICES J Mar Sci 57:393-402

Nyman RM, Conover DO (1988) The relation between spawning season and the recruitment of young-of-the-year bluefish, Pomatomus saltatrix, to New York. Fish Bull 86: $237-250$

Oliver JD, Holeton GF, Chua KE (1979) Overwinter mortality of fingerling smallmouth bass in relation to size, relative energy stores, and environmental temperature. Trans Am Fish Soc 108:130-136

Post JR, Evans DO (1989) Size-dependent overwinter mortality of young-of-the-year yellow perch (Perca flavescens): laboratory, in situ, and field experiments. Can J Fish Aquat Sci 46:1958-1968

Post JR, Parkinson EA (2001) Energy allocation strategy in young fish: allometry and survival. Ecology 82:1040-1051

Reimers N (1963) Body condition, water temperature, and overwinter survival of hatchery-reared trout in Convict Creek, California. Trans Am Fish Soc 92:39-46

Schultz ET, Conover DO (1997) Latitudinal differences in somatic energy storage: adaptive responses to seasonality in an estuarine fish (Atherinidae: Menidia menidia). Oecologia. 109:516-529

Schultz ET, Conover DO (1999) The allometry of energy reserve depletion: test of a mechanism for size dependent winter mortality. Oecologia 119:474-483

Sheridan MA (1988) Lipid dynamics in fish: aspects of absorption, transportation, deposition and mobilization. Comp Biochem Physiol B 90:679-690

Shuter BJ, MacLean JA, Fry FEJ, Reiger HA (1980) Stochastic simulation of temperature effects on first-year survival of smallmouth bass. Trans Am Fish Soc 109:1-34

Skajaa K, Fernoe A, Folkvord A (2003) Swimming, feeding and predator avoidance in cod larvae (Gadus morhua L.): trade-offs between hunger and predation risk. The big fish bang. In: Browman H, Skiftesvik A (eds) Proc 26th Annu Larval Fish Conf. Institute of Marine Research, Bergen, p 105-121

Slater JJ (2004) Winter energetics of young-of-the-year bluefish (Pomatomus saltatrix). MS thesis, University of North Carolina at Wilmington, Wilmington

Smith W, Berrien P, Potthoff T (1994) Spawning patterns of bluefish, Pomatomus saltatrix, in the northeast continental shelf ecosystem. Bull Mar Sci 54:8-16

Sogard SM (1997) Size-selective mortality in the juvenile stage of teleost fishes: a review. Bull Mar Sci 60:1129-1157

Sogard SM, Olla BL (2000) Endurance of simulated winter conditions by age- 0 walleye pollock: effects of body size, water temperature and energy stores. J Fish Biol 56: $1-21$

StatSoft (2001) Statistica: system reference. StatSoft, Tulsa, OK

Thompson JT, Bergersen EP, Carlson CA, Kaeding LR (1991) Role of size, condition, and lipid content in the overwinter survival of age-0 Colorado squawfish. Trans Am Fish Soc 120:346-353 